\title{
Coma with Vertical Gaze Palsy: Relevance of Angio-CT in Acute Percheron Artery Syndrome
}

\author{
M. Godanic A. Auci ${ }^{b} \quad$ T. Torri ${ }^{b} \quad$ S. Jensen ${ }^{a} \quad$ M. Del Sette \\ Departments of a Neurology and ${ }^{b}$ Radiology, Ospedale Civico di Carrara, Carrara, \\ and 'Department of Neurology, Ospedale Civico S. Andrea, La Spezia, Italy
}

\section{Key Words}

Percheron $\cdot$ Vertical gaze $\cdot$ Relevance $\cdot$ Coma $\cdot$ Angio-CT

\begin{abstract}
Background: A 63-year-old woman with chronic atrial fibrillation treated with warfarin was admitted to emergency for coma and complete vertical gaze palsy.

Investigations: Brain CT and MRI, echo-colour Doppler sonography of the supraaortic vessels, angio-CT of the intracranial vessels, EEG, transesophageal echocardiogram, biohumoral tests. Brain CT and MRI scans showed bilateral thalamic lesions with involvement of the right midbrain; EEG showed a diffuse alpha rhythm prevalent on the posterior regions; echo-colour Doppler sonography of the supraaortic vessels showed marked reduction of blood flow in the right vertebral artery; angio-CT scans showed occlusion of the right vertebral artery and a significant filling defect of the first part of the right posterior cerebral artery $(\mathrm{P} 1)$ from which the artery of Percheron arises. A follow-up angio-CT showed a complete recanalization of P1.
\end{abstract}

Diagnosis: Percheron artery syndrome.

Treatment and Management: Aspirin, neurorehabilitation.

\section{The Case}

A 63-year-old, Caucasian woman with chronic atrial fibrillation treated with warfarin was referred to our hospital for neurological evaluation on New Year's Eve. The symptoms had begun while the patient had been sitting in front of the fireplace, with sudden onset of somnolence and inability to maintain an upright position. After a few minutes, the patient was helped into bed and presented sudden loss of consciousness.

Judging from a first neurological evaluation, she had a Glasgow Coma Scale score of 7. She moved the upper and lower limbs upon a painful stimulus without being able to localize it. She had no fever and no meningeal signs. The eyes were maintained closed and she appeared to be in a state of deep sleep, breathing heavily and snoring. The passive examination of the ocular movements showed complete vertical gaze palsy (fig. 1). Deep tendon reflexes were symmetrical; plantar reflex was bilaterally normal. No other pathological signs were present. 


\begin{tabular}{l|l|l|l} 
Cose Reports in & $\begin{array}{l}\text { Case Rep Neurol 2010;2:74-79 } \\
\text { D0I: } 10.1159 / 000315835\end{array}$ & Published online: June 8, 2010 & $\begin{array}{l}\odot \text { 2010 S. Karger AG, Basel } \\
\text { ISSN 1662-680X } \\
\text { www.karger.com/crn }\end{array}$ \\
\hline
\end{tabular}

The following laboratory tests were unremarkable: complete blood cell count, glycaemia, electrolytes, liver enzymes, creatinine, ammonia, arterial blood gas including carboxyhaemoglobin value, ethanol and benzodiazepine levels; INR was 1.92. Brain CT scan performed on the day of admission was normal, in particular without early signs of ischemia. EEG performed on the following day showed a diffuse alpha rhythm prevalent on the posterior regions and a beta rhythm on the anterior regions with some occasionally interspersed theta waves. No lateralized abnormality was found in the EEG recording. Echo-colour Doppler sonography of the supraaortic vessels showed orthodromic and asymmetric blood flow in the vertebral arteries with marked reduction in the right vertebral artery. A new brain CT scan performed $24 \mathrm{~h}$ later showed an ill-defined hypodensity in both thalami. A brain MRI performed the same day demonstrated a large hyperintensity, on axial flair images, of the right mesencephalic peduncle and of the thalamic nuclei bilaterally (fig. 2).

An angio-CT of the intracranial vessels, performed two days after the patient's admission, confirmed occlusion of the right vertebral artery with a patent basilar artery but showed stenosis of the first part (P1) of the right posterior cerebral artery (fig. $3 \mathrm{a}, \mathrm{b}$ ). A second angio-CT done three weeks later confirmed occlusion of the right vertebral artery while the filling defect of the right posterior cerebral artery was no longer evident (fig. 3c, d).

Transesophageal echocardiography was normal, showing no cardiac source of embolism and no patent foramen ovale.

\section{Discussion of Diagnosis}

The patient presented an acute onset of coma and vertical gaze palsy with no other focal signs. Blood examinations excluded a possible metabolic, toxic, infective, endocrine or iatrogenic aetiology of the comatose state. Brain CT scan and MRI showed bilateral thalamic lesions with involvement of the right midbrain that can be caused by several conditions: ischaemic stroke, deep cerebral vein thrombosis, thiamine deficiency, cerebral lupus, toxoplasmosis, cysticercosis, cerebral syphilitic gumma and tumours [1]. Presence of an alpha activity on the EEG can be seen in patients with vascular brainstem lesions, cerebral concussion, cerebral hypoxia and drug intoxication. It is known that alpha activity in comatose patients with drug intoxication is distributed predominantly over the frontal lobes. On the contrary, alpha activity in patients with brainstem lesions has similar features to the one of healthy normal subjects with a higher expression in the posterior regions [2]. In our patient, alpha activity was predominant on the posterior regions supporting the hypothesis of a vascular brainstem lesion. The coagulation parameters were only close to therapeutic range (INR $=1.92$ ). Angio-CT scans showed occlusion of the right vertebral artery and a filling defect of the $\mathrm{P} 1$ segment of the right posterior cerebral artery that disappeared after 25 days. On the basis of clinical, neuroimaging and neurovascular findings, the only possible diagnosis was an ischaemic stroke in the territory of the artery of Percheron due to an embolic occlusion or hypoperfusion following a thrombosis of the right vertebral artery.

The arterial supply to the thalamus is provided by perforating branches from the posterior cerebral artery and the posterior communicating artery. The P1 segment of the posterior cerebral artery, which connects the basilar artery with the posterior communicating artery, is anatomically a prolongation of the basilar artery. Kaplan and Ford named this arterial segment 'the mesencephalic artery' [3]; Percheron called it 'basilar communicating artery' [4].

The paramedian thalamic arteries arise from the basilar communicating artery and may share a common origin with the superior paramedian mesencephalic arteries that supply the medial areas of the upper brainstem [5]. 


\begin{tabular}{l|l|l|l} 
Case Reports in & $\begin{array}{l}\text { Case Rep Neurol 2010;2:74-79 } \\
\text { Dol: } 10.1159 / 000315835\end{array}$ & Published online: June 8, 2010 & $\begin{array}{l}\text { ○ 2010 S. Karger AG, Basel } \\
\text { ISSN 1662-680X } \\
\text { www.karger.com/crn }\end{array}$ \\
\hline
\end{tabular}

The arterial configuration at the origin of the paramedian pedicle varies greatly. Percheron described three types (ig.4) [4]. Type I is a symmetrical arrangement: one paramedian thalamic artery arises on each side from the corresponding basilar communicating artery. Type II is asymmetrical: the right and left paramedian thalamic arteries arise from the same basilar communicating artery, separately or by a common trunk which then bifurcates. In this case, the two paramedian thalamic territories are supplied via only one basilar communicating artery. Finally, in type III, an arterial arcade connects the two basilar communicating arteries and gives rise to the paramedian arteries.

In addition to the medial thalamic nuclei, these paramedian thalamic and mesencephalic arteries supply the interpeduncular nucleus, the decussation of the superior cerebellar peduncles, the medial part of the red nucleus, the third and fourth cranial nerve nuclei and the anterior portion of the periaqueductal grey matter [5]. Occlusion of type II artery of Percheron often results in bilateral infarctions in the middle aspects of thalami and brainstem. In fact, when paramedian thalamic infarcts are bilateral, there is either an unpaired thalamic perforator or the occlusion involves the bifurcation of the basilar artery [6]. This condition is rare and none of the reports published through the years were able to demonstrate in vivo an occlusion of the artery of Percheron, which could only be presumed in patients with bilateral thalamic lesions. Roitberg et al. [1] were the only authors who demonstrated a patent unpaired thalamic perforator artery on superselective digital subtraction angiography in a patient with bilateral thalamic infarcts.

Patients with paramedian thalamic and midbrain infarctions have a specific clinical picture: loss of consciousness or somnolence at stroke onset, frequently followed by eye movement disturbances such as upward gaze palsy and/or skew deviation with pupillary abnormalities, but few motor or sensory deficits. Long-term follow-up showed orientation and concentration deficits, memory dysfunction and behavioural disturbances [7]. According to Kumral et al., the main cause of bilateral thalamic infarction is small artery disease followed by cardioembolism [8]. Aetiological diagnosis was done in our case only two days after the onset, as in most cases, because of complex and nonspecific clinical presentation; nonetheless, the presence of residual stenosis of the basilar communicating artery followed by complete recanalization allowed us to diagnose an embolic occlusion.

In our patient, the ischaemic lesions have been caused by a partial occlusion of the basilar communicating artery giving an occlusion or hypoperfusion of the artery of Percheron. It is highly probable that the embolus departed during the thrombogenesis process of the ipsilateral vertebral artery. As in previous reports of paramedian thalamic and midbrain infarctions, symptom onset was characterized by somnolence, unsteadiness and subsequent coma with vertical gaze palsy.

Various names, such as 'top of the basilar syndrome' [6] and 'mesencephalothalamic syndrome' [7], have been used to describe the clinical syndromes associated with paramedian thalamic and midbrain infarction. The clinical picture is variable and can present in various confusing ways, so careful attention to the differential diagnosis could be extremely important for the benefit of patients.

\section{Treatment and Management}

As the patient was admitted with an INR value over 1.7, i.v. thrombolysis was not done, even if intraarterial thrombolysis could have been considered. In any case, we 


\begin{tabular}{l|l|l|l} 
Cose Reports in & $\begin{array}{l}\text { Case Rep Neurol 2010;2:74-79 } \\
\text { Dol: } 10.1159 / 000315835\end{array}$ & Published online: June 8, 2010 & $\begin{array}{l}\odot \text { 2010 S. Karger AG, Basel } \\
\text { ISSN 1662-680X } \\
\text { www.karger.com/crn }\end{array}$ \\
\hline
\end{tabular}

suggest that an urgent vascular diagnosis, by means of urgent angio-CT, could have helped in the decision-making process.

\section{Conclusion}

In this paper we present a case of bilateral paramedian thalamic and right mesencephalic infarction. When bilateral thalamic infarcts are found, occlusion of the artery of Percheron should be considered as the main cause [9]. In the majority of cases, the main clinical features of the occlusion of the artery of Percheron are coma and vertical gaze palsy due to the involvement of the rostral midbrain tegmentum including the interstitial nucleus of Cajal $[10,11]$.

In our case, the occlusion of the artery of Percheron was only indirectly diagnosed, since this artery is often below the resolution of the angio-CT.

We think that performing an angio-CT could be a successful choice when a patient with unconsciousness and vertical gaze palsy is brought in for neurological evaluation. In these cases, the diagnosis is often made many hours or even days after the clinical onset, while the appropriate diagnosis should be done at the earliest possible stage, since the efficacy of thrombolysis decreases rapidly as time passes by [12]. If the diagnosis is made in the shortest time possible, the thrombolytic therapy can still be done and the outcome can be fairly good [13]. Thus we strongly suggest to always consider angio-CT in the evaluation of emergency patients with sudden onset of coma and vertical gaze palsy.

\section{Acknowledgements}

We thank Mrs Ilaria Falchetto for her precious help with figure 1 and Mrs Maria Xiarchou for technical help with the acquisition of angio-CT images (fig. 2).

Fig. 1. Passive examination of the ocular movements: this manoeuvre tests the oculocephalic reflex. a-c Natural response in normal patients, referred to as doll's eye sign (the gaze deviates contralaterally in the opposite direction of where the head is turned). $\mathbf{d}$, e An abnormal response is present when the eyes remain fixed on the horizontal or vertical axis during the passive movement of the head.
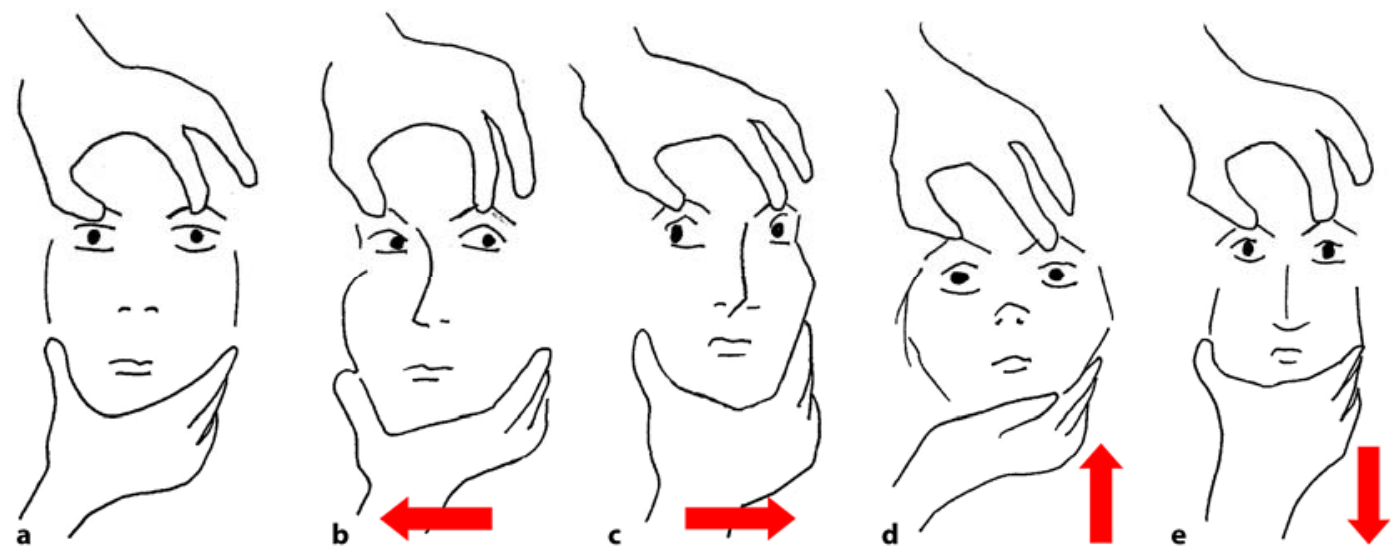


\begin{tabular}{l|l|l|l} 
Cose Reports in & $\begin{array}{l}\text { Case Rep Neurol 2010;2:74-79 } \\
\text { D01: 10.1159/000315835 }\end{array}$ & Published online: June 8, 2010 & $\begin{array}{l}\text { @ 2010 S. Karger AG, Basel } \\
\text { ISSN 1662-680X } \\
\text { www.karger.com/crn }\end{array}$ \\
\hline
\end{tabular}

Fig. 2. MR imaging: axial FLAIR images show hyperintensities in the paramedian thalamic regions extending to the right mesencephalic peduncle.

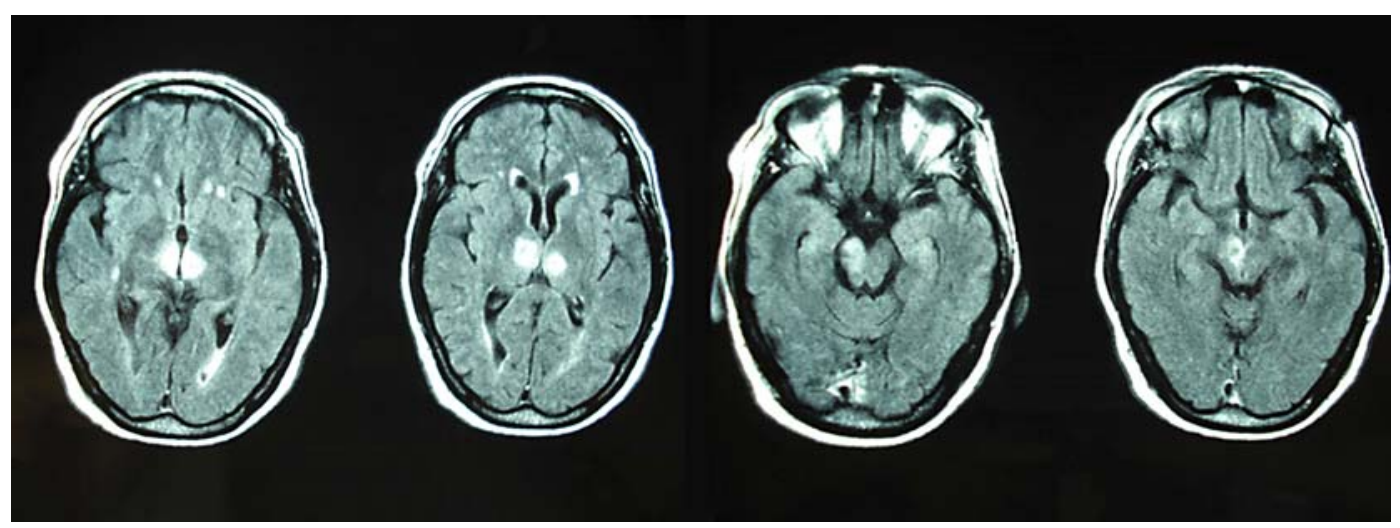

Fig. 3. Angio-CT scan. a Lack of visualization of the right vertebral artery with patent basilar artery (BA = basilar artery, VA = left vertebral artery). b Focally stenotic first tract of the right posterior cerebral artery. c Persistent occlusion of the right vertebral artery with patent basilar artery after three weeks. d Stenosis resolution of first tract of the right posterior cerebral artery after three weeks.
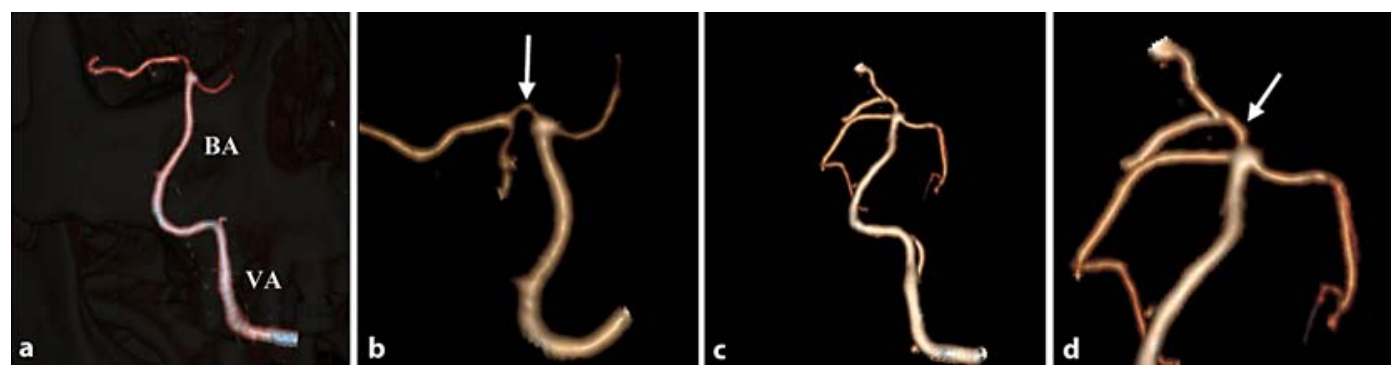

Fig. 4. Anatomic variations of the arterial supply to the paramedian thalamic-mesencephalic region as described by Percheron [4]. a Common variation, many small perforating vessels arising from the P1 segments of both posterior cerebral arteries. b Artery of Percheron variant, arising from the P1 tract of a single posterior cerebral artery and supplying both thalami. c Arcade variant, with several small perforating branches arising from a single artery that bridges the P1 segments of both posterior cerebral arteries.
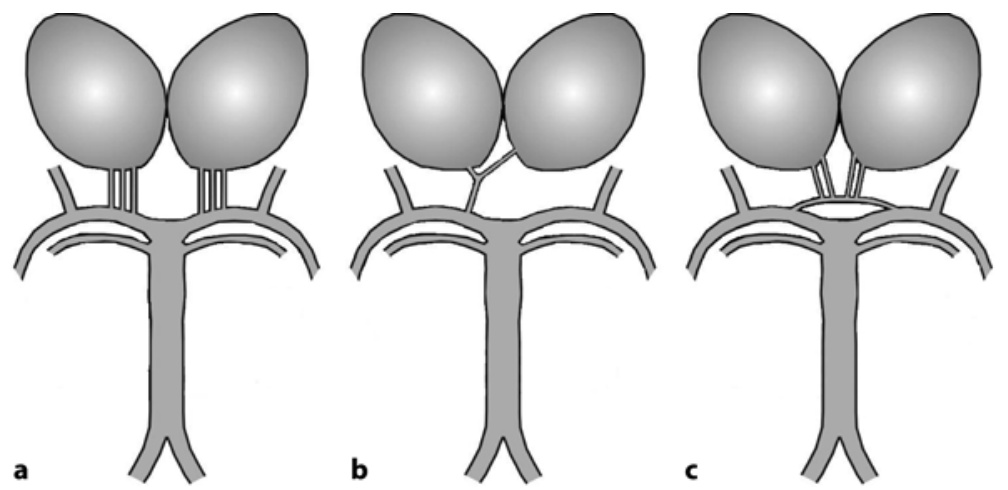


\begin{tabular}{l|l|l|l} 
Cose Reports in & $\begin{array}{l}\text { Case Rep Neurol 2010;2:74-79 } \\
\text { Dol: } 10.1159 / 000315835\end{array}$ & Published online: June 8, 2010 & $\begin{array}{l}\text { @ 2010 S. Karger AG, Basel } \\
\text { ISSN 1662-680X } \\
\text { www.karger.com/crn }\end{array}$ \\
\hline
\end{tabular}

\section{References}

1 Roitberg BZ, Tuccar E, Alp MS: Bilateral paramedian thalamic infarct in the presence of an unpaired thalamic perforating artery. Acta Neurochir (Wien) 2002;144:301-304.

$>2$ Yazawa S, Kawasaki S, Kanemaru A, et al: Bilateral paramedian thalamo-midbrain infarction showing electroencephalographic alpha activity. Intern Med 2001;40:443-448.

3 Kaplan HA, Ford OH: The Brain Vascular System. Amsterdam, Elsevier, 1966.

4 Percheron G: Les artères du thalamus humain. II. Artères et territoires thalamiques paramédians de l'artère basilaire communicante. Rev Neurol (Paris) 1976;132:309-324.

5 Waterston JA, Stark RJ, Gilligan BS: Paramedian thalamic and midbrain infarction: the 'mesencephalothalamic syndrome'. Clin Exp Neurol 1987;24:4553.

-6 Castaigne P, Lhermitte F, Buge A, et al: Paramedian thalamic and midbrain infarct: clinical and neuropathological study. Ann Neurol 1981;10:127-148.

7 Perren F, Clarke S, Bogousslavsky J: The syndrome of combined polar and paramedian thalamic infarction. Arch Neurol 2005;62:1212-1216.

$>8$ Kumral E, Evyapan D, Balkir K, Kutluhan S: Bilateral thalamic infarction. Clinical, etiological and MRI correlates. Acta Neurol Scand 2001;103:35-42.

9 Matheus MG, Castillo M: Imaging of acute bilateral paramedian thalamic and mesencephalic infarcts. AJNR Am J Neuroradiol 2003;24:2005-2008.

10 Ben Slamia L, Jemaa HB, Benammou S, Tlili-Graiess K: Occlusion of the artery of Percheron: clinical and neuroimaging correlation. J Neuroradiol 2008;35:244245.

11 Monet P, Garcia PY, Saliou G, et al: Bithalamic infarct: is there an evocative aspect? Radioclinical study. Rev Neurol (Paris) 2009;165:178-184.

12 Krampla W, Schmidbauer B, Hruby W: Ischaemic stroke of the artery of Percheron. Eur Radiol 2007;18:192-194.

13 Kostanian V, Cramer SC: Artery of Percheron thrombolysis. AJNR Am J Neuroradiol 2007;28:870-871.

M.G. and S.J. have equally contributed to the manuscript authorship. 